\title{
Pain Agreements and Healthcare Utilization in a Veterans Affairs Primary Care Population: A Retrospective Chart Review
}

\author{
Cynthia Kay (D) - Erica Wozniak · Alice Ching · Joanne Bernstein
}

Received: March 16, 2018 / Published online: May 11, 2018

(C) The Author(s) 2018

\begin{abstract}
Introduction: The prevalence of chronic pain is enormous. In America, the management of chronic pain and opioids remains a critical focus. Guidelines recommend pain agreements as part of the management of chronic pain and opioids; however, evidence of improvement in patient outcomes is lacking. An aspect of patient outcome includes utilization of healthcare resources, such as emergency department visits and hospitalizations. It remains uncertain whether the use of pain agreements lessens healthcare utilization.

Methods: Retrospective chart review of a Midwest Veterans Affairs primary care clinic. Subjects were veterans on chronic opioids between 1 April 2014 and 1 April 2015. Outcome measures included emergency department visits,
\end{abstract}

Enhanced digital features To view enhanced digital features for this article go to https://doi.org/10.6084/ m9.figshare.6189218.

C. Kay $(\varangle) \cdot$ A. Ching

Clement J Zablocki VA Medical Center, Milwaukee, WI, USA

e-mail: ckay@mcw.edu

C. Kay $\cdot$ A. Ching $\cdot$ J. Bernstein

Medical College of Wisconsin, Milwaukee, WI, USA

C. Kay · E. Wozniak

Center for Patient Care and Outcomes Research,

MCW, Milwaukee, WI, USA hospitalizations, clinic visits, telephone triage, telephone/secure messages, and nurse visits.

Results: The charts of 635 veterans on chronic opioids were reviewed. Of these, 295 were on a pain agreement. There were no significant differences in demographics, medical, or psychiatric diagnoses between patients with and without pain agreements. There were significant differences in opioid schedule and number of opioids based on pain agreement $(p<0.01)$. Patients on pain agreements did not utilize healthcare resources less than patients without a pain agreement. In fact, patients on pain agreements were likely to have more telephone calls, secure messages, and nurse visits compared with patients not on an agreement $(p=0.02)$.

Conclusions: Pain agreements are becoming standard of care for chronic pain management. However, there continues to be a lack of evidence demonstrating improvement in healthcare outcomes with their use, despite guideline recommendations. Further studies are needed to examine specific patient outcomes, such as overdose and death, in regard to pain agreements.

Funding: Advancing a Healthier WisconsinPatient-Centered Outcomes Research Program.

Keywords: Chronic pain; Primary care; Utilization; Veterans 


\section{INTRODUCTION}

Chronic pain affects 100 million Americans [1]. Guidelines continue to recommend pain agreements as part of the management of chronic pain. Pain agreements, sometimes referred to as opioid treatment agreements or pain contracts, are documents signed by patients and their providers that outline expectations and obligations regarding the use of opioids for pain [2]. There is often a belief that pain agreements may curb unnecessary contact between patient and provider, although evidence to support this is not only needed, but the utility of pain agreements in improving outcomes also remains inconclusive $[3,4]$. As such, it is unknown whether the use of pain agreements may decrease healthcare utilization in a veterans population.

Healthcare utilization has almost exclusively been examined in terms of hospitalizations, emergency department visits, specialty visits, and medications. Telephone calls, secure messages, and nurse visits, which are other forms of healthcare resources, are integral parts of primary care and rarely studied.

The objectives of this study are to describe healthcare utilization of a veterans population based on pain agreement status. It is hypothesized that patients on pain agreements for chronic opioids utilize fewer healthcare resources than those not on an agreement.

\section{METHODS}

This was a retrospective chart review of primary care patients at a Midwest Veterans Affairs (VA) Medical Center. Potential subjects were identified through the VA Informatics and Computing Infrastructure, and variables were extracted from the electronic medical records. Subjects were at least 18 years old and prescribed opioids for at least 3 months between 1 April 2014 and 1 April 2015. Patients with active cancer, on hospice, prescribed an opioid within 6 months of surgery, or not seen in clinic at least once in the established time frame were excluded. Patient demographics, diagnoses, pain agreement status, provider characteristic (physician or advanced practice provider), and healthcare utilization (emergency department visits, hospitalizations, clinic visits, telephone triage, telephone/secure messages, nurse visits) were obtained.

Demographic and clinical characteristics were compared by pain agreement status using chi-square and $t$ tests for categorical and continuous variables, respectively. Descriptive statistics and bivariate analyses (chi-square or Fisher's exact tests, where appropriate) were used to compare instances of healthcare utilization as counts by pain agreement status. All procedures performed were in accordance with the ethical standards of the institutional research committee and with the 1964 Helsinki Declaration and its later amendments or comparable ethical standards. Informed consent was waived by the Clement J. Zablocki VA Medical Center Institutional Review Board.

\section{RESULTS}

The first 635 patients who met the inclusion criteria were included to meet statistical power requirements. These patients included those on pain agreements and those prescribed chronic opioids but who were not on an agreement.

There were 295 patients on a pain agreement. There were no significant differences in age, race, provider type, history of substance abuse, or the presence of depression, PTSD, or anxiety between patients with and without pain agreements. There were significant differences in opioid schedule and number of opioids based on the pain agreement (Table 1).

Patients on pain agreements were likely to have more telephone calls, secure messages, and nurse visits compared with patients not on an agreement $(p=0.02)$. There were no other statistically significant differences in healthcare utilization measures based on pain agreement status (Table 2).

\section{DISCUSSION}

Pain agreements have been in use for years and are recommended by most organizations as part 
Table 1 Patient characteristics by pain agreement status

\begin{tabular}{|c|c|c|c|}
\hline & Non-pain agreement $(N=322)$ & Pain agreement $(N=295)$ & $p$ value \\
\hline Age, mean (SD) & $61.9(13.2)$ & $61.9(11.8)$ & 0.94 \\
\hline Race & & & 0.20 \\
\hline White (\%) & $221(68.6 \%)$ & $209(70.8 \%)$ & \\
\hline Gender & & & 0.53 \\
\hline Male (\%) & $318(98.8 \%)$ & $289(98.0 \%)$ & \\
\hline Provider type & & & 0.97 \\
\hline Physician & $185(57.5 \%)$ & $169(57.3 \%)$ & \\
\hline Faculty only & $322(100 \%)$ & $295(100 \%)$ & - \\
\hline Mental health team & $134(41.6 \%)$ & $146(49.5 \%)$ & 0.05 \\
\hline MME & & & 0.21 \\
\hline$>50$ & $86(26.7 \%)$ & $99(33.6 \%)$ & \\
\hline Opioid schedule & & & $<0.01$ \\
\hline II & $78(24.2 \%)$ & $232(78.6 \%)$ & \\
\hline Number of opioids & & & $<0.01$ \\
\hline More than 1 & $4(1.2 \%)$ & $63(21.4 \%)$ & \\
\hline Psychiatric diagnosis & $222(68.9 \%)$ & $221(74.9 \%)$ & 0.10 \\
\hline Depression & $125(38.8 \%)$ & $137(46.4 \%)$ & 0.06 \\
\hline Diabetes & $105(32.6 \%)$ & $99(33.6 \%)$ & 0.80 \\
\hline Anxiety & $41(12.7 \%)$ & $40(13.6 \%)$ & 0.76 \\
\hline PTSD & $70(21.7 \%)$ & $65(22.0 \%)$ & 0.93 \\
\hline Hypertension & $223(69.3 \%)$ & $213(72.2 \%)$ & 0.42 \\
\hline CKD/ESRD & $34(9.9 \%)$ & $34(11.5 \%)$ & 0.70 \\
\hline COPD/asthma & $60(18.6 \%)$ & $56(19.0 \%)$ & 0.91 \\
\hline $\mathrm{CAD} / \mathrm{CHF}$ & $68(21.1 \%)$ & $75(25.4 \%)$ & 0.21 \\
\hline Neuropathy & $38(11.8 \%)$ & $39(13.2 \%)$ & 0.59 \\
\hline Obesity & $126(39.1 \%)$ & $115(39.0 \%)$ & 0.97 \\
\hline Arthritis/spinal stenosis & $155(48.1 \%)$ & $156(52.9 \%)$ & 0.24 \\
\hline $\begin{array}{l}\text { History of substance use } \\
\text { disorder }\end{array}$ & $56(17.4 \%)$ & $56(19.0 \%)$ & 0.61 \\
\hline Tobacco use & $108(33.5 \%)$ & $96(32.5 \%)$ & 0.79 \\
\hline Service connection & $188(58.4 \%)$ & $178(60.3 \%)$ & 0.62 \\
\hline
\end{tabular}

$M M E$ Morphine milligram equivalent, PTSD post-traumatic stress disorder, $C K D$ chronic kidney disease, ESRD end-stage renal disease, $C O P D$ chronic obstructive pulmonary disease, $C A D$ coronary artery disease, $C H F$ congestive heart failure 
Table 2 Healthcare utilization by long-term opioid treatment agreement

\begin{tabular}{|c|c|c|c|}
\hline & No opioid agreement, $N=322$ & Opioid agreement, $N=295$ & $p$ value \\
\hline ED visits & & & 0.13 \\
\hline 0 & $173(53.7 \%)$ & $167(56.6 \%)$ & \\
\hline 1 & $69(21.4 \%)$ & $45(15.3 \%)$ & \\
\hline $2+$ & $80(24.8 \%)$ & $83(28.1 \%)$ & \\
\hline Hospitalizations & & & 0.18 \\
\hline 0 & $265(82.3 \%)$ & $230(78.0 \%)$ & \\
\hline $1+$ & $57(17.7 \%)$ & $65(22.0 \%)$ & \\
\hline Clinic visits & & & 0.64 \\
\hline 1 & $73(22.7 \%)$ & $58(19.7 \%)$ & \\
\hline $2-3$ & $179(55.6 \%)$ & $168(56.9 \%)$ & \\
\hline $4+$ & $70(21.7 \%)$ & $69(23.4 \%)$ & \\
\hline Telephone triage & & & 0.75 \\
\hline 0 & $221(68.6 \%)$ & $199(67.5 \%)$ & \\
\hline $1+$ & $101(31.4 \%)$ & $96(32.5 \%)$ & \\
\hline Messages/nurse visits ${ }^{a}$ & & & 0.02 \\
\hline $0-2$ & $176(54.7 \%)$ & $146(49.5 \%)$ & \\
\hline $3-5$ & $89(27.6 \%)$ & $70(23.7 \%)$ & \\
\hline $6+$ & $57(17.7 \%)$ & $79(26.8 \%)$ & \\
\hline
\end{tabular}

$E D$ emergency department

${ }^{a}$ Includes telephone calls, secure messages, and nurse visits

of the management of patients with chronic pain [5]. Past studies have shown that providers utilize pain agreements for various reasons, such as to increase confidence when prescribing opioids, for self-protection, and to decrease patient contact related to pain medications $[6,7]$. The latter is the reason we hypothesized that patients on pain agreements would utilize fewer healthcare resources compared with patients not on pain agreements. The results from this study did not support the hypothesis. The results are, however, similar to those found in a pain agreement study on a civilian population [8]. However, in that study, patients on pain agreements had fewer hospitalizations.

A possible explanation for the increased utilization of telephone calls, secure messages, and nurse visits in this study may be the VA Patient
Aligned Care Team (PACT). The PACT is the Veterans Health Administration's patient-centered medical home (PCMH) model. The unit of the PACT is the teamlet, which consists of the primary care provider, nurse, clinical associate (health technician, licensed practical nurse), and administrative associate [9]. One purpose of the PACT model is to offer patients more access to their providers, through a variety of avenues. The increased contact seen in this study is likely a result of the inherent nature of the model itself.

The absence of any other differences in healthcare utilization by pain agreement status is a reminder that the management of chronic pain is often challenging and complex. Chronic pain, like many other medical conditions, may not be static and may require multi- and 
interdisciplinary teams for effective treatment. The differences in opioid schedule and number of opioids by pain agreement may suggest that providers use agreements for subjective purposes, like security and self-protection. This may also explain why all patients on chronic opioids were not on a pain agreement. In addition, at the time of the study, the clinic encouraged providers to utilize pain agreements for patients on chronic opioids, but the decision to do so was ultimately up to each provider.

There are a number of limitations to this study. First, this was a retrospective chart review of a single VA medical center. It is uncertain whether the population can be generalizable to other VA centers or other community clinics. Second, we could not limit counts of healthcare utilization to those only related to pain. Also, some veterans seek non-VA cares for various reasons. We were unable to account for emergency department visits, hospitalizations, and clinic visits that took place at community healthcare systems or even other VA hospitals.

\section{CONCLUSION}

As pain agreements become standard of care for chronic pain management, it seems inevitable that all patients on chronic opioids will be on an agreement, regardless of demographics, diagnoses, or opioids. In the same vein, providers will likely implement pain agreements because organizations or clinics require them to do so instead of by their own clinical judgment [10-12]. The absence of any reduction in healthcare utilization with pain agreements is not confirmation of a lack of potential benefit. It does, however, call for further studies to examine patient outcomes, such as opioid-related overdose and death, as objective evidence for pain agreement remains unproven.

\section{ACKNOWLEDGEMENTS}

The information provided in this study does not represent the views of the Department of
Veterans Affairs or the United States Government. We thank the participants of the study.

Funding. This study and article processing charges were supported by the Advancing a Healthier Wisconsin-Patient-Centered Outcomes Research Program. All authors had full access to all of the data in this study and take complete responsibility for the integrity of the data and accuracy of the data analysis.

Authorship. All named authors meet the International Committee of Medical Journal Editors (ICMJE) criteria for authorship for this article, take responsibility for the integrity of the work as a whole, and have given their approval for this version to be published.

Disclosures. Cynthia Kay, Erica Wozniak, Alice Ching, and Joanne Bernstein have nothing to disclose.

Compliance with Ethics Guidelines. All procedures performed in studies involving human participants were in accordance with the ethical standards of the institutional and/or national research committee and with the 1964 Helsinki Declaration and its later amendments or comparable ethical standards. Informed consent was waived by the Clement J. Zablocki VA Medical Center Institutional Review Board.

Data Availability. The primary data used to support the findings of this study have not been made available because of patient privacy and restrictions from the Veterans Health Administration.

Open Access. This article is distributed under the terms of the Creative Commons Attribution-NonCommercial 4.0 International License (http://creativecommons.org/licenses/ by-nc/4.0/), which permits any noncommercial use, distribution, and reproduction in any medium, provided you give appropriate credit to the original author(s) and the source, provide a link to the Creative Commons license, and indicate if changes were made. 


\section{REFERENCES}

1. Institute of medicine report from the committee on advancing pain research, care, and education: relieving pain in America, a blueprint for transforming prevention, care, education and research. The National Academies Press, 2011. http://books. nap.edu/openbook.php?record_id=13172\&page $=1$. Accessed 25 Feb 2018.

2. Fishman SM, Bandman TB, Edwards A, Borsook D. The opioid contract in the management of chronic pain. J Pain Symptom Manage. 1999;18(1):27-37.

3. Elliott AM, Smith BH, Penny KI, Smith WC, Chambers WA. The epidemiology of chronic pain in the community. Lancet. 1999;354(9186):1248-52.

4. Arnold RM, Han PK, Seltzer D. Opioid contracts in chronic nonmalignant pain management: objectives and uncertainties. Am J Med. 2006;119(4):292-6.

5. Dowell D, Haegerich TM, Chou R. CDC guideline for prescribing opioids for chronic pain-United States, 2016. JAMA. 2016;315(15):1624-45.

6. Starrels JL, $\mathrm{Wu} \mathrm{B}$, Peyser D, et al. It made my life a little easier: primary care providers' beliefs and attitudes about using opioid treatment agreements. J Opioid Manag. 2014;10(2):95.
7. Fagan MJ, Chen JT, Diaz JA, Reinert SE, Stein MD. Do internal medicine residents find pain medication agreements useful? Clin J Pain. 2008;24(1):35-8.

8. Kay C, Wozniak E, Bernstein J. Utilization of health care services and ambulatory resources associated with chronic noncancer pain. Pain Med. 2017;18(7):1236-46.

9. Patient Aligned Care Team (PACT) Handbook. Department of Veterans Affairs. 2014. https://www. va.gov/vhapublications/ViewPublication.asp?pub_ ID=2977. Accessed 29 Jan 2018.

10. VA/DoD Clinical Practice Guideline for Opioid Therapy for Chronic Pain. Veterans affairs. 2017. https://www.healthquality.va.gov/guidelines/Pain/ cot/VADoDOTCPGProviderSummary022817.pdf. Accessed 30 Jan 2018.

11. State-by-State Summary of Opioid Prescribing Regulations and Guidelines. Arizona Department of Health Services. 2017. http://www.azdhs.gov/ documents/prevention/womens-childrens-health/ injury-prevention/opioid-prevention/appendix-bstate-by-state-summary.pdf. Accessed 13 Feb 2018.

12. New prescribing law for treatment of acute and chronic pain. New Jersey Academy of Family Physician. 2018. https://www.njafp.org/content/ new-prescribing-law-treatment-acute-and-chronicpain. Accessed 13 Feb 2018. 